\title{
The catalytic mechanism of the Suzuki-Miyaura reaction
}

\author{
Juliet M. Macharia ${ }^{\dagger}$, Chetan Joshi ${ }^{\dagger}$, Joseph A. Izzo, Victor Wambua, Sungjin Kim, Jennifer S. \\ Hirschi*, Mathew J. Vetticatt* \\ Department of Chemistry, Binghamton University, Vestal, NY 13850, USA \\ *Corresponding author. Email: jhirschi@binghamton.edu (J.S.H) vetticatt@binghamton.edu \\ (M.J.V) \\ $\dagger$ Authors contributed equally
}

Abstract: Experimental and theoretical ${ }^{13} \mathrm{C}$ kinetic isotope effects are utilized to obtain atomistic insight into the catalytic mechanism of the $\mathrm{Pd}\left(\mathrm{PPh}_{3}\right)_{4}$ catalyzed Suzuki-Miyaura reaction of aryl halides and aryl boronic acids. Under catalytic conditions, we establish that oxidative addition of aryl bromides occurs to a 12-electron monoligated palladium complex $\left(\mathrm{Pd}\left(\mathrm{PPh}_{3}\right)\right)$. For aryl iodides, the first irreversible step in the catalytic cycle precedes oxidative addition and is shown to be binding of the iodoarene to $\mathrm{Pd}\left(\mathrm{PPh}_{3}\right)$. Our results suggest that the commonly proposed oxidative addition to the 14-electron $\mathrm{Pd}\left(\mathrm{PPh}_{3}\right)_{2}$ complex can occur only in the presence of excess added ligand or under stoichiometric conditions. The transmetalation step, under catalytic conditions, is shown to proceed via a tetracoordinate boronate (8B4) intermediate with a Pd-O-B linkage.

One Sentence Summary: The catalytic mechanism of the Suzuki-Miyaura reaction is resolved using ${ }^{13} \mathrm{C}$ kinetic isotope effects.

Main Text: Palladium catalyzed cross-coupling reactions, between an organic halide and an organometallic reagent, that forge carbon-carbon bonds constitute one of the central pillars of modern-day organic synthesis $(1)$. Three sequential mechanistic events define the general catalytic cycle of most palladium catalyzed cross-coupling reactions: (a) oxidative addition (OA) of the organic halide to palladium (0) to form a palladium (II) complex; (b) transmetalation (TM), i.e. transfer of the organic portion of the organometallic reagent to the palladium (II) center; and (c) reductive elimination (RE) to form the new carbon-carbon bond and regenerate palladium (0) catalyst (2). High-resolution insight into the fine details of these fundamental steps is critical to the optimization of existing methodologies and development of novel catalytic cross-coupling reactions.

The palladium catalyzed Suzuki-Miyaura (S-M) reaction between an organic halide (1) and a boronic acid (2) has emerged as a versatile and robust cross-coupling process with broad application in the synthesis of high-value pharmaceuticals and fine chemicals (Fig. 1A) (3-5). The privileged status of the S-M reaction has inspired several high-quality experimental and theoretical investigations into the mechanism, leading to a constantly evolving view of this catalytic process (Fig. 1B) (6-14). OA has been extensively studied by a number of research groups (15-24) and the general consensus is that for simple phosphine ligands such as triphenylphosphine OA of $\mathbf{1}$ occurs to a palladium (0) center ligated to two phosphine ligands $\left(\mathrm{PdL}_{2}\right)$ via $\mathbf{P d L} \mathbf{L}_{2}-\mathbf{O A}_{\mathbf{T s}}$ to yield a $\mathrm{PdL}_{2}$ ArX OA complex (Fig. 1C) (15). Alternatively, experimental (18) and computational studies $(22,23)$ have also suggested the possible involvement of a coordinatively unsaturated 12-electron $\mathrm{PdL}_{1}$ complex as the active catalytic species in OA (Fig. 1C, PdL $\mathbf{1}-\mathbf{O A}_{\mathrm{TS}}$ ). 
A
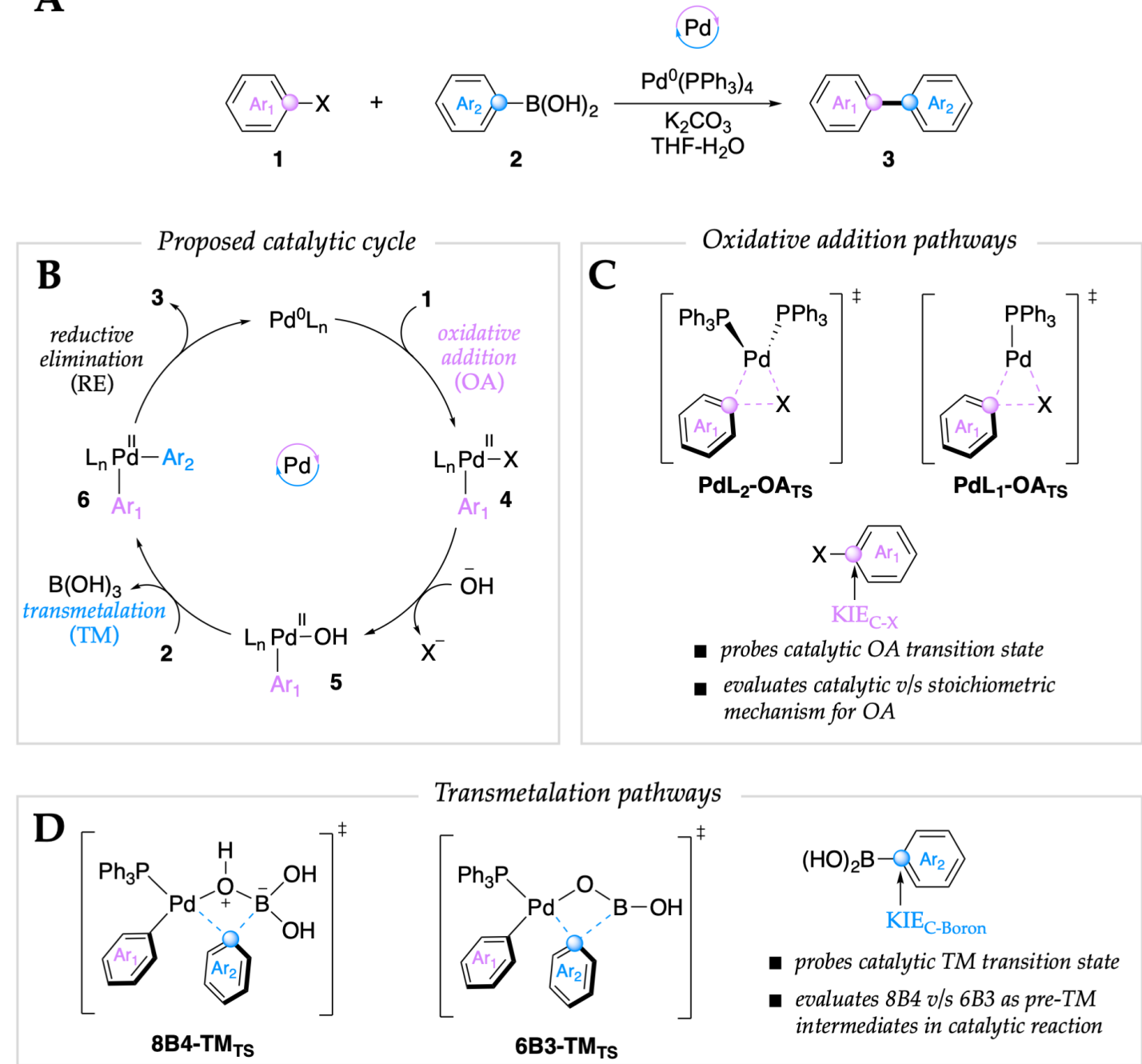

Transmetalation pathways

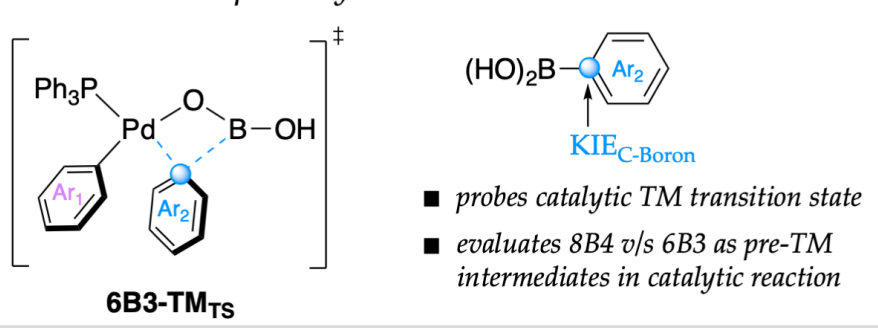

Fig. 1. Key mechanistic features of the catalytic Suzuki-Miyaura reaction (A) Prototypical Suzuki-Miyaura reaction of aryl halide and aryl boronic acid catalyzed by a palladium ( 0 ) catalyst. (B) Widely accepted mechanism of the Suzuki-Miyaura reaction involving three key mechanistic events - oxidative addition, transmetalation, and reductive elimination. (C) Two possible pathways for oxidative addition involving either a 14-electron $\mathrm{PdL}_{2}$ or a 12-electron $\mathrm{PdL}_{1}$ palladium (0) complex. (D) Two viable pathways for transmetalation involving intermediates containing Pd-OB linkages.

Elegant kinetic studies by Carrow and Hartwig, involving stoichiometric reactions of isolated OA complexes, have revealed that $\mathbf{4}$ is likely converted to a hydroxopalladium species $\mathbf{5}$ prior to the TM step by reaction with aqueous hydroxide generated in the THF-water reaction mixture containing an inorganic base such as $\mathrm{K}_{2} \mathrm{CO}_{3}$ (25). Groundbreaking low-temperature NMR studies by Thomas and Denmark have shown that association of $\mathbf{2}$ and $\mathbf{5}$ leads to the formation of two key pre-TM intermediates containing Pd-O-B linkages - a tetracoordinate boronate (8B4) complex and a tricoordinate boronic acid (6B3) complex (12). However, since both intermediates readily convert to product 3 through TM (via 8B4-TM $\mathbf{M}_{\text {Ts }}$ or $\mathbf{6 B 3 - T M}$ Ts, Fig. 1D) and subsequent $\mathrm{RE}$ upon warming to room temperature, the exact identity of the pre-TM intermediate in the catalytic reaction remains ambiguous. Additional kinetic and computational studies by Denmark 
and co-workers suggest that (a) both 8B4-TM $\mathbf{M}_{\mathbf{T S}}$ or $\mathbf{6 B 3}-\mathbf{T M} \mathbf{M}_{\mathrm{TS}}$ are viable TM pathways depending on the concentration of ligand in solution, and (b) the TM event occurs only after dissociation of a ligand from these pre-TM intermediates (13). The final step in the catalytic cycle, C-C bondforming RE, is extremely facile and thought to be accelerated by hydroxide ions in solution (26).

The currently accepted catalytic cycle for the S-M reaction (vide supra) is based predominantly on mechanistic observations from stoichiometric reactions of putative intermediate complexes $(12,15-19,25)$. This approach is necessitated due to the low concentration of these intermediates under typical catalytic conditions $(<2 \mathrm{~mol} \%$ palladium catalyst). Utilization of mechanistic observations from stoichiometric studies to interpret the catalytic mechanism is valid only if the intermediate complexes form under catalytic conditions. Kinetic studies can often provide valuable mechanistic information under catalytic conditions $(7,8)$; but this does not include atomistic information about the TS of the elementary steps. Computational studies provide detailed insight into the TS of each step of the catalytic S-M reaction (9, 10, 21, 22, 26-29). However, experimental validation of the calculated TSs in the catalytic S-M reaction has remained 15 elusive.

A powerful experimental probe of transition structures in carbon-carbon bond-forming reactions is the determination of ${ }^{13} \mathrm{C}$ kinetic isotope effects (KIEs) at natural abundance (30-32). Despite this, there are limited examples of the use of ${ }^{13} \mathrm{C} \mathrm{KIEs}$ among the vast literature of mechanistic studies of cross-coupling reactions (33-41). Given that each step in the proposed catalytic cycle of the S-M reaction involves bonding change at a carbon atom, determination of ${ }^{13} \mathrm{C}$ KIEs for the two bond-forming carbon atoms (Fig. 1, KIE $\mathrm{C}_{\mathrm{X}}$ and $\mathrm{KIE}_{\mathrm{C}-\mathrm{Boron}}$ ) can provide vital insight into the transition structures of key steps under standard (catalytic) conditions. We describe herein a combined experimental and theoretical ${ }^{13} \mathrm{C}$ KIE study of the S-M reaction that provides unprecedented insight into the catalytic mechanism of this important reaction. Importantly, we find that ${ }^{13} \mathrm{C}$ KIEs are an exceptionally sensitive probe of the transition states involving bondmaking or bond-breaking between carbon and palladium - enabling the first experimental characterization of the transition structure of the OA and TM steps under catalytic conditions.

Probing the transition state geometry of $O A$ in the catalytic $S$ - $M$ reaction: Oxidative addition of aryl bromides to palladium (0) is highly exergonic and, barring some examples (42), is generally considered an irreversible step in the catalytic cycle. Therefore, ${ }^{13} \mathrm{C} \mathrm{KIEs} \mathrm{determined} \mathrm{for}$ the aryl bromide in the S-M reaction should reflect the nature of the OA TS. We chose the prototypical S-M reaction of aryl bromide 1a with boronic acid $\mathbf{2 a}$ catalyzed by $\mathrm{Pd}\left(\mathrm{PPh}_{3}\right)_{4}$ for determination of ${ }^{13} \mathrm{C}$ KIEs for the aryl bromide (1a) via quantitative NMR analysis. Under catalytic conditions (Fig. 2A, conditions \# 1), we observe a significant normal ${ }^{13} \mathrm{C} \mathrm{KIE}$ on the carbon atom attached to the bromine $\left(\mathrm{KIE}_{\mathrm{C}-\mathrm{Br}}=1.020(1)\right)$. This result is qualitatively consistent with OA being the first irreversible step in the catalytic cycle and provides an experimental benchmark to probe the exact nature of the OA transition state using density functional theory (DFT) calculations. 
A

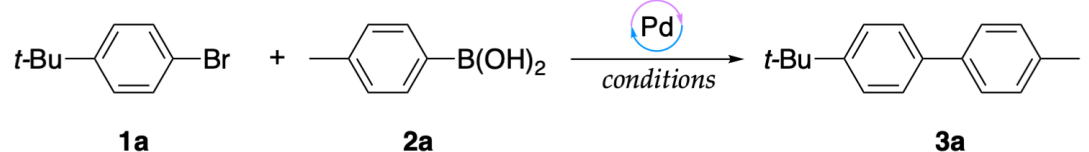

1 a

$2 a$

$3 a$
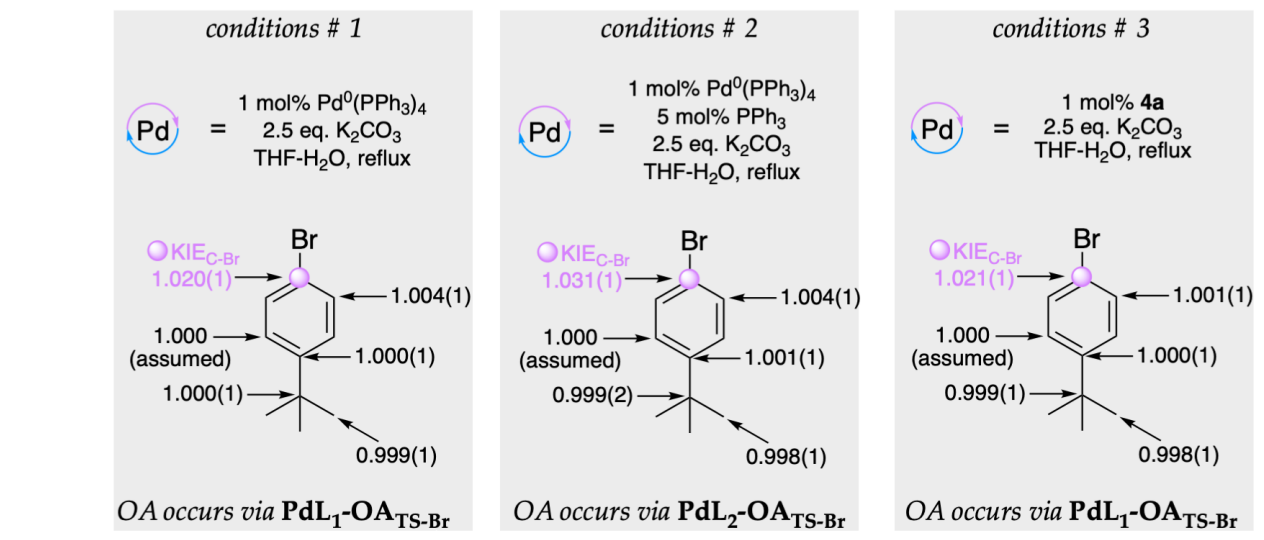

B
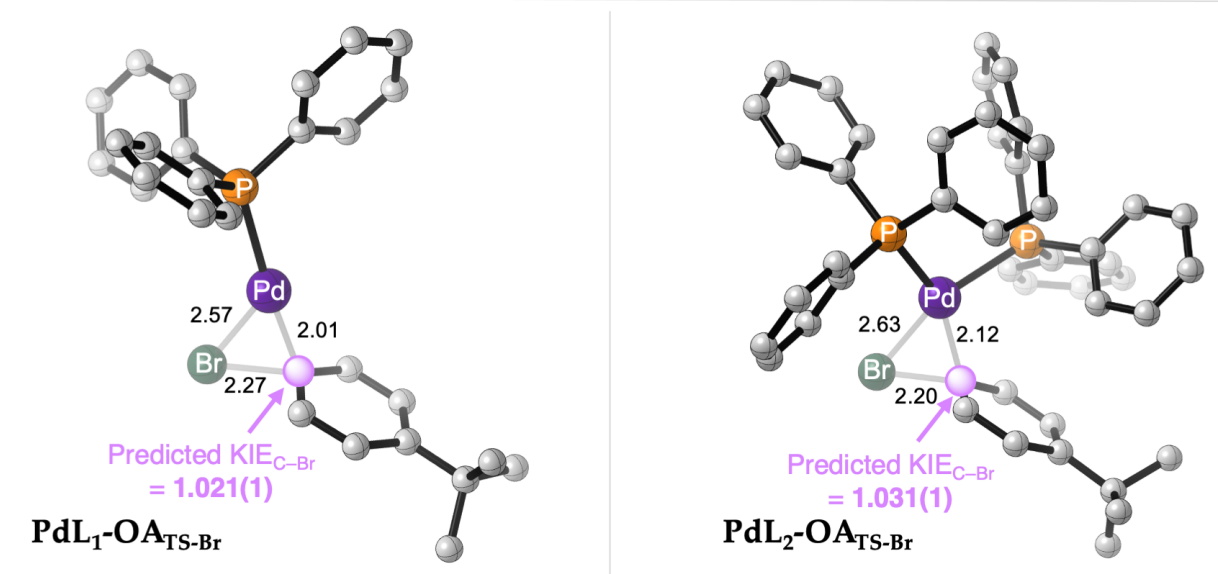

C

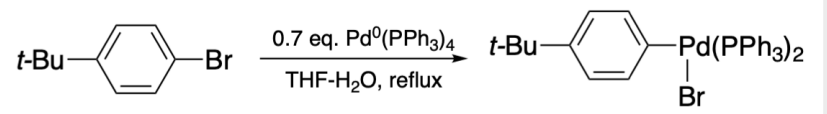

1a

$4 a$

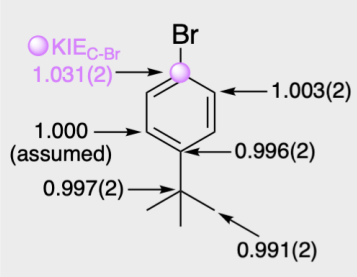

Experimental KIE benchmark for $\mathbf{P d L}_{2}-\mathbf{O A}$ TS-Br

Fig. 2. Probing the oxidative addition step in the catalytic Suzuki-Miyaura reaction (A) ${ }^{13} \mathrm{C}$ KIE experiments to probe the OA TS as a function of ligand concentration and catalyst type. (B) Calculated TSs and predicted ${ }^{13} \mathrm{C}$ KIEs for OA of 1a to mono- and diligated palladium (0) with key bond distances shown in angstroms $(\AA)$. Predicted KIEs are expressed as an average from 12 DFT methods. (C) Stoichiometric experiment to establish a benchmark ${ }^{13} \mathrm{C}$ KIE value for OA to $\mathrm{PdL}_{2}$. Experimental ${ }^{13} \mathrm{C}$ KIEs are shown as an average of 12 measurements from two independent 
experiments. Experimental and predicted KIEs represent the $95 \%$ confidence range for the last digit shown in parentheses.

Key bond-distances and predicted KIEs for all transition structures presented in this study are displayed as an average from calculations implemented using 12 routinely employed DFT methods used to study these systems (see Supplementary Information for computational details). This ensures that the theoretical evaluation of our experimental results is not an artifact of one particular DFT method. For the quantitative interpretation of $\mathrm{KIE}_{\mathrm{C}-\mathrm{Br}}$ (Fig 2A, conditions \# 1), we calculated the TS for OA of $\mathbf{1 a}$ to both monoligated (PdL $\left.\mathbf{1}-\mathbf{O A} \mathbf{A}_{\mathrm{TS}-\mathbf{B r}}\right)$ and diligated $\left(\mathbf{P d L}_{\mathbf{2}}-\mathbf{O A}_{\mathrm{TS}}\right.$ -

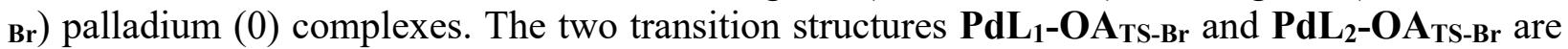
similar in terms of bond-making and bond-breaking distances (Fig. 2B). The $\mathrm{Pd}-\mathrm{C}$ bond-forming

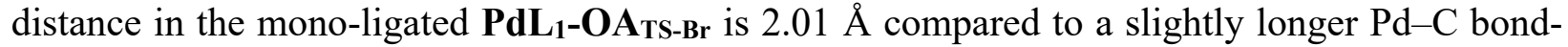
forming distance of $2.12 \AA$ in the more electron-rich diligated $\mathbf{P d L} \mathbf{L}_{2}-\mathbf{O A}_{\mathbf{T S}}-\mathbf{B r}$. The greater extent of C-Pd bond-formation in $\mathbf{P d L}_{\mathbf{1}}-\mathbf{O} \mathbf{A}_{\text {TS-Br }}$ also corresponds to a more advanced $\mathrm{C}-\mathrm{Br}$ bond15 breaking distance of $2.27 \AA$; $\mathrm{C}-\mathrm{Br}$ bond-breaking distance in PdL2-OA $\mathbf{O}$ Ts-Br is $2.20 \AA$. Intriguingly, $\mathrm{KIE}_{\mathrm{C}-\mathrm{Br}}$ is exceptionally sensitive to these subtle differences in structure - the predicted $\mathrm{KIE}_{\mathrm{C}-\mathrm{Br}}$ for $\mathbf{P d L}_{\mathbf{1}}-\mathbf{O A}_{\mathrm{TS}-\mathrm{Br}}$ is 1.021(1) compared to a predicted $\mathrm{KIE}_{\mathrm{C}-\mathrm{Br}}$ of 1.031(1) for $\mathbf{P d L}_{2}-\mathbf{O A}_{\mathrm{TS}-\mathrm{Br}}$ (Fig. 2B). Based on the excellent agreement of experimental and predicted KIEs for $\mathbf{P d L}_{1}-\mathbf{O A}_{\mathrm{TS}-\mathrm{Br}}$, our results suggest that OA in the catalytic S-M reaction (Fig. 2A, conditions \# 1) occurs to a $\mathrm{PdL}_{1}$ species. Importantly, this result quantitatively rules out $P d L_{2}$ as the active species that undergoes $O A$ in the catalytic reaction.

To further support our finding that $\mathrm{OA}$ occurs to $\mathrm{PdL}_{1}$ in the catalytic reaction, we conducted three additional experiments. The first experiment involves determination of $\mathrm{KIE}_{\mathrm{C}-\mathrm{Br}}$ for the stoichiometric $\mathrm{OA}$ of $\mathbf{1 a}$ to $\mathrm{Pd}\left(\mathrm{PPh}_{3}\right)_{4}$ to form the well-characterized $\mathrm{PdL}_{2}\left(\mathrm{Ar}_{1}\right)(\mathrm{Br})$ complex (Fig 2C) (43). This stoichiometric experiment delivers an experimental benchmark KIE C- $_{\text {- }}$ $\mathrm{Br}$ value to unambiguously characterize $\mathbf{P d L}_{\mathbf{2}}-\mathbf{O A}_{\mathrm{TS}-\mathrm{Br}}$. Gratifyingly, the $\mathrm{KIE}_{\mathrm{C}-\mathrm{Br}}$ for this reaction is 1.031(2) - a value consistent with the predicted $\mathrm{KIE}_{\mathrm{C}-\mathrm{Br}}$ for $\mathbf{P} \mathbf{d L}_{\mathbf{2}}-\mathbf{O} \mathbf{A A}_{\mathrm{Ts}}-\mathrm{Br}$. Importantly, this result provides unequivocal evidence that $\mathrm{OA}$ to $\mathrm{Pd}\left(\mathrm{PPh}_{3}\right)_{4}$ occurs via different mechanisms under catalytic (Fig 2A, conditions \# 1) versus stoichiometric (Fig. 2C) conditions. In the second experiment, the catalytic S-M reaction of $1 \mathbf{a}$ and $\mathbf{2 a}$ was performed with added $\mathrm{PPh}_{3}$ ligand (Fig. $2 \mathrm{~A}$, conditions \# 2). Excess ligand is expected to decrease the probability of OA occurring to a $\mathrm{PdL}_{1}$ by driving the $\mathrm{PdL}_{1} / \mathrm{PdL}_{2}$ equilibrium towards the $\mathrm{PdL}_{2}$ species. Consistent with our hypothesis, the $\mathrm{KIE}_{\mathrm{C}-\mathrm{Br}}$ for this reaction is 1.031(1) - a value consistent with the predicted $\mathrm{KIE}_{\mathrm{C}-}$ $\mathrm{Br}$ for $\mathbf{P d L}_{2}-\mathbf{O A} \mathbf{A}_{\mathrm{TS}-\mathrm{Br}}$. The reaction with excess ligand is significantly more sluggish, suggesting that $\mathrm{OA}$ to $\mathrm{PdL}_{1}$ is a faster process than $\mathrm{OA}$ to $\mathrm{PdL}_{2}$.(22) Finally, we performed the catalytic S-M reaction of $1 \mathbf{a}$ and $\mathbf{2 a}$ using the isolated complex $\mathbf{4 a}$ as the catalyst (Fig. 1A, conditions \# 3 ). Observation of an experimental $\mathrm{KIE}_{\mathrm{C}-\mathrm{Br}}$ of 1.021(1) illustrates that OA occurs via PdL1-OAts-Br even when a $\mathrm{PdL}_{2}$ complex is explicitly used as the catalyst for the S-M reaction.

Next, we turned our attention to studying the S-M reaction of aryl iodide $\mathbf{1 b}$ and boronic acid 2a. We determined $\mathrm{KIE}_{\mathrm{C}-\mathrm{I}}$ under standard catalytic conditions similar to 'conditions \# 1' used for the bromo derivative (1a). The first key result is the near-unity $\mathrm{KIE}_{\mathrm{C}-\mathrm{I}}$ of $\sim 1.003(1)$ (see Fig. 3 , conditions \# 1). This suggests there is no bonding change at this carbon in the first irreversible step of the catalytic cycle - a result qualitatively inconsistent with OA as the first irreversible step for 1b. Oxidative addition of aryl iodides to palladium (0) is generally considered an irreversible process. Therefore, the absence of a significant normal $\mathrm{KIE}_{\mathrm{C}-\mathrm{I}}$ suggests the first irreversible step 
for $\mathbf{1 b}$ likely precedes OA, i.e. binding of $\mathbf{1 b}$ to palladium (0) is irreversible and has a higher barrier than the ensuing OA step.

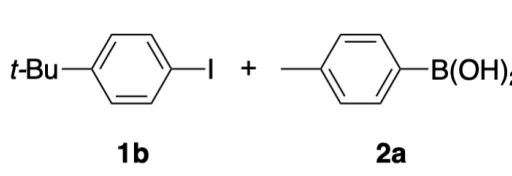

key TSs in $\mathrm{PdL}_{1}$ pathway
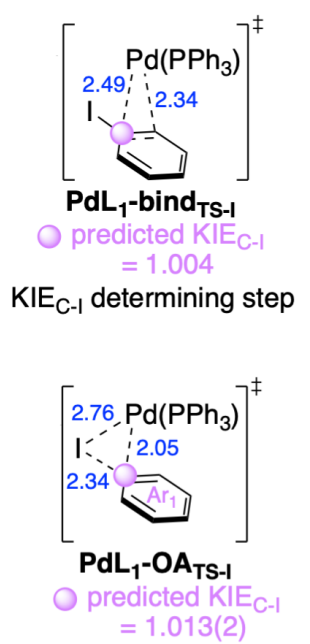

Pd
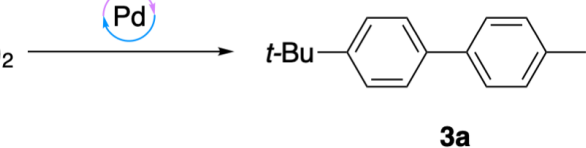

3a

key TS in $\mathbf{P d L}_{2}$ pathway

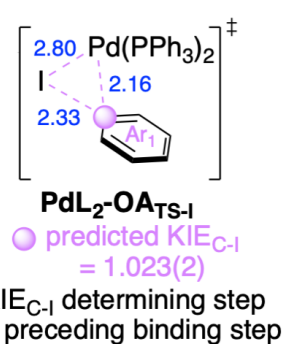

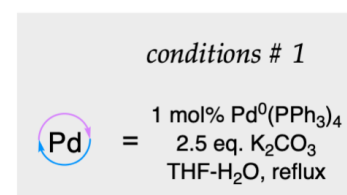

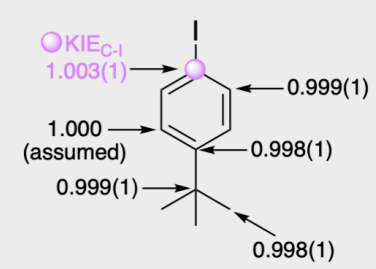

First irreversible step precedes $O A$ likely PdL $_{\mathbf{1}}$-bind $_{\text {TS-I }}$

Fig. 3. Using ${ }^{13} \mathrm{C}$ KIEs to probe contribution of concurrent pathways for oxidative addition in the catalytic Suzuki-Miyaura reaction of iodoarenes and boronic acids. ${ }^{13} \mathrm{C} \mathrm{KIE}$ experiments to probe the OA TS as a function of ligand concentration for aryl iodides along with predicted ${ }^{13} \mathrm{C}$ KIEs for all relevant TSs involved in the OA of $\mathbf{1 b}$ under these conditions with key bond distances shown in angstroms $(\AA)$. Experimental ${ }^{13} \mathrm{C}$ KIEs are shown as an average of 12 measurements from two independent experiments. Experimental and predicted KIEs represent the $95 \%$ confidence range for the last digit, shown in parentheses.

For the quantitative interpretation of the $\mathrm{KIE}_{\mathrm{C}-\mathrm{I}}$, we modeled the OA step of $\mathbf{1 b}$ to both $\mathrm{PdL}_{1}$ (PdL 1 -OA $\mathbf{A}_{\text {TS-I }}$ ) and $\mathrm{PdL}_{2}$ (PdL 2 -OA $\mathbf{A}_{\text {TS-I }}$ ) complexes (Fig. 3A) using the theoretical methods described previously. Predicted $\mathrm{KIE}_{\mathrm{C}-\mathrm{I}}$ for these two TSs are 1.013(2) and 1.023(2) respectively, both of which are inconsistent with the experimental KIE $\mathrm{C}_{\text {-I }}$ value. Next, we located PdL $\mathbf{L}_{\mathbf{1}}$-bind $_{\text {Ts- }}$ $\mathbf{I}$, the transition structure for formation of the $\eta^{2}$ binding complex between $\mathrm{PdL}_{1}$ and $\mathbf{1 b}$. Predicted $\mathrm{KIE}_{\mathrm{C}-\mathrm{I}}$ for $\mathbf{P d L}_{\mathbf{1}}$-bind $\mathbf{b S - I}_{\text {TS }}$ is 1.004 , which is in excellent agreement with the experimental KIE $\mathrm{K}_{\mathrm{I}-\mathrm{I}}$. No such TS could be located for $\mathrm{PdL}_{2}$ (IRC calculations from $\mathbf{P d L} \mathbf{d}_{\mathbf{2}}-\mathbf{O} \mathbf{A}_{\text {TS-I }}$ result in separate starting materials) - consistent with prior investigations suggesting that $\mathrm{OA}$ of aryl halides to $\mathrm{PdL}_{2}$ occurs without a preceding binding event $(18,22,23)$. These results lend strong support to OA of $\mathbf{1 b}$ to palladium (0) occurring via irreversible binding of $\mathbf{1 b}$ to $\mathrm{PdL}_{1}$ followed by a facile $\mathrm{OA}$ event.

To further confirm that the $\mathrm{PdL}_{1}$ pathway is operative for $\mathbf{1 b}$, we determined $\mathrm{KIE}_{\mathrm{C}-\mathrm{I}}$ in the presence of $5 \mathrm{~mol} \%$ added $\mathrm{PPh}_{3}$ (similar to Fig 2A, conditions \# 2). Unlike in the case of aryl bromide 1a, under conditions of excess ligand, we did not observe a KIE $\mathrm{C}_{\text {-I }}$ corresponding to $\mathbf{P d L}_{2-}$ OA $_{\text {TS-I }}$; instead, we observed an experimental KIE $\mathrm{C}_{-\mathrm{I}}$ of 1.008(1) (Fig. 3, conditions \# 2, $\mathrm{x}=5$ ). A measurement greater than the predicted $\mathrm{KIE}_{\mathrm{C}-\mathrm{I}}$ for PdL1-bind $\mathbf{P d S}_{\mathbf{I}}$ (the KIE-determining step in the 
$\mathrm{PdL}_{1}$ pathway) but significantly smaller than the predicted $\mathrm{KIE}_{\mathrm{C}-\mathrm{I}}$ of 1.023(2) for $\mathbf{P d L}_{2}-\mathbf{O A}_{\text {TS-I }}$ (likely the KIE-determining step in the $\mathrm{PdL}_{2}$ pathway). This result can be interpreted as being consistent with $\sim 85 \%$ of the reaction proceeding via the $\mathrm{PdL}_{1}$ pathway and $\sim 15 \%$ via the $\mathrm{PdL}_{2}$ pathway. Increasing ligand concentrations to 20 and $40 \mathrm{~mol} \%$ resulted in $\mathrm{KIE}_{\mathrm{C}-\mathrm{I}}$ values of $1.016(1)$, and 1.022(4) (Fig. 3, conditions \#2, $\mathrm{x}=20,40$ ), respectively - reflecting the increasing contribution of the $\mathrm{PdL}_{2}$ pathway in the catalytic reaction.

Collectively, these results provide support for OA of both aryl bromides and iodides occurring to a 12 electron $\mathrm{PdL}_{1}$ species under standard catalytic conditions. This $\mathrm{OA}$ step is preceded by the formation of an $\eta^{2}$ binding complex between $\mathrm{PdL}_{1}$ and the aryl halide. The key difference between aryl bromides and aryl iodides is the relative energies of the binding versus the OA step. Experimental KIE $\mathrm{C}_{\mathrm{C}-\mathrm{Br}}$ values (Fig. 2) suggest formation of the $\eta^{2}$ binding complex has a lower barrier than the OA step. In contrast, the weaker C-I bond results in the lowering of the OA barrier relative to that of the binding step (23). The $\mathrm{PdL}_{2}$ pathway is operational only in the presence of excess $\mathrm{PPh}_{3}$ ligand or under stoichiometric conditions.

A
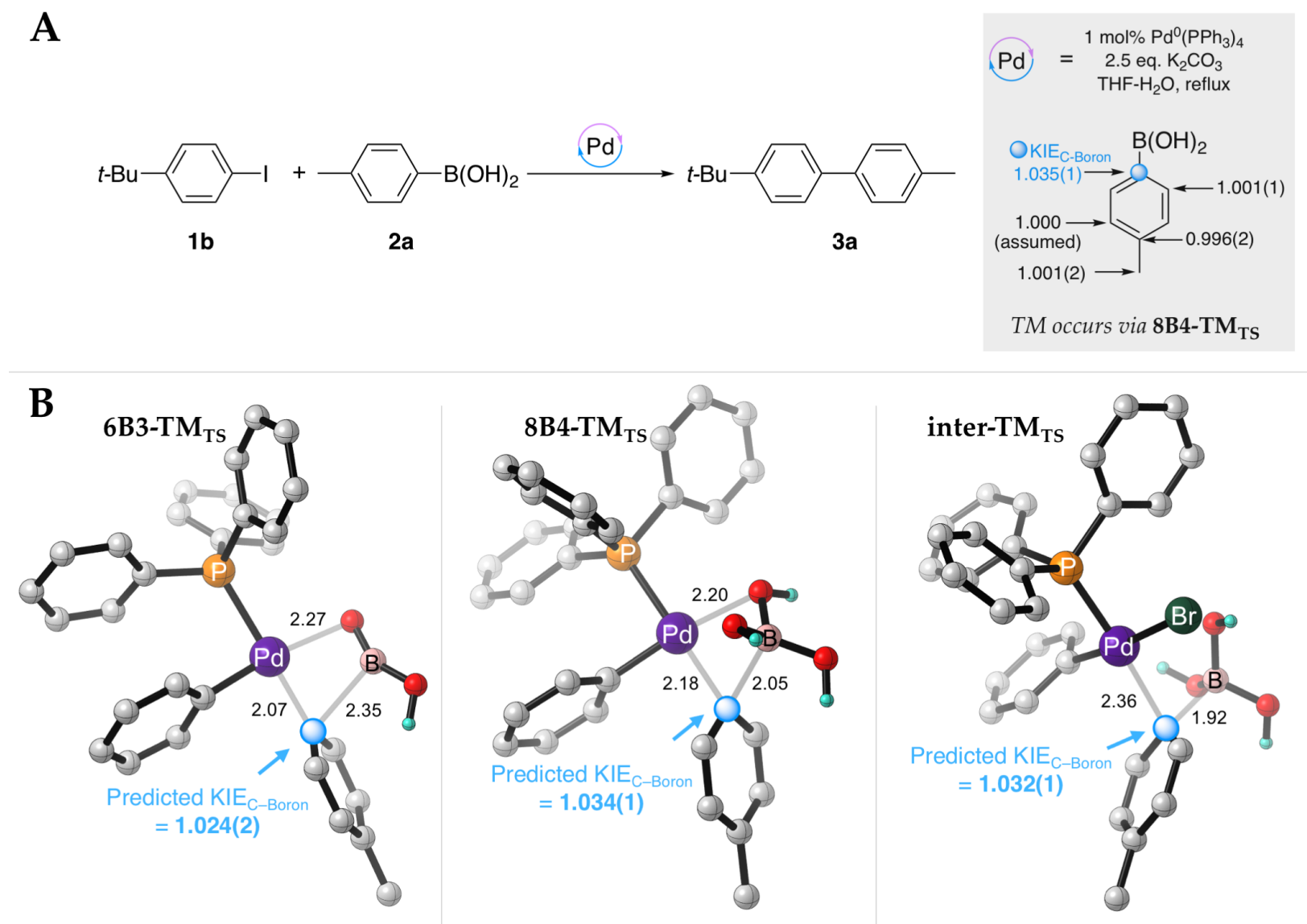

15 Fig. 4. Probing the transmetalation step in the catalytic Suzuki-Miyaura reaction from boronic acid KIEs (A) ${ }^{13} \mathrm{C}$ KIE experiments to probe the TM TS in the catalytic S-M reaction of 1b and 2a. (B) Calculated TSs and predicted ${ }^{13} \mathrm{C}$ KIEs for possible TM TSs with key bond distances shown in angstroms $(\AA)$. Experimental ${ }^{13} \mathrm{C}$ KIEs are shown as an average of 12 measurements from two independent experiments. Experimental and predicted KIEs represent the $95 \%$ confidence range for the last digit shown in parentheses. 
Probing the transition state geometry of TM in the catalytic S-M reaction: Having established the catalytic mechanism of OA, we turned our attention to the investigation of the TM step under catalytic conditions. In particular, we questioned whether we could distinguish between aryl transfer from the $8 \mathrm{~B} 4\left(\mathbf{8 B} 4-\mathbf{T M} \mathbf{T S}_{\mathrm{Ts}}\right)$ versus the $6 \mathrm{~B} 3\left(\mathbf{6 B 3}-\mathbf{T M} \mathbf{M}_{\mathrm{TS}}\right)$ pre-TM intermediates by determining the ${ }^{13} \mathrm{C}$ KIE on the carbon atom of 2 (Fig. 1, KIE ${ }_{C-B o r o n}$ ) that migrates from boron to palladium during the TM event. We speculated that $\mathrm{KIE}_{\mathrm{C}-\mathrm{Boron}}$ will be different for these two TSs due to the difference in nucleophilicity of the aryl group in the respective intermediates. We chose the prototypical S-M reaction of aryl iodide $\mathbf{1 b}$ and boronic acid 2a catalyzed by $\mathrm{Pd}\left(\mathrm{PPh}_{3}\right)_{4}$ for determination of $\mathrm{KIE}_{\mathrm{C}-\mathrm{B} o r o n}$ via NMR analysis. Observation of a significant $\mathrm{KIE}_{\mathrm{C}-\mathrm{B} o r o n}$ of 1.035(1) (Fig. 4A) is qualitatively consistent with TM being the first irreversible step in the catalytic cycle for $2 \mathbf{a}$.

For the quantitative interpretation of this KIE, we modeled the intramolecular TM event (Fig. 4B) from both the tetracoordinate boronate complex $\left(\mathbf{8 B}\right.$ - $\left.-\mathbf{T M} \mathbf{M}_{\mathrm{TS}}\right)$ and the tricoordinate boronic acid complex $\left(\mathbf{6 B 3}-\mathbf{T M} \mathbf{M}_{\mathrm{TS}}\right)$. In $\mathbf{8 B} 4-\mathbf{T} \mathbf{M}_{\mathrm{TS}}$, the forming Pd-C bond distance $\left(r_{\mathrm{Pd}-\mathrm{C}}\right)$ is 2.18 $\AA$ and the breaking B-C bond $\left(r_{\mathrm{B}-\mathrm{C}}\right)$ is $2.05 \AA$. The corresponding distances in 6B3-TM $\mathbf{M}_{\mathrm{TS}}$ are 2.07 $\AA$ and $2.35 \AA$, respectively. Therefore, TM from the $8 \mathrm{~B} 4$ intermediate has an earlier transition state than the $6 \mathrm{~B} 3$ intermediate - consistent with the more nucleophilic migrating aryl group in $8 \mathrm{~B} 4$. We also observed a clear correlation between $r_{\mathrm{Pd}-\mathrm{C}}$ in the transition structures and $\mathrm{KIE}_{\mathrm{C}-\mathrm{Boron}}-$ increased proximity of the migrating carbon atom to the palladium center in 6B3-TMTS (compared to 8B4-TM $\mathbf{M}_{\mathrm{TS}}$ ) results in a lower predicted $\mathrm{KIE}_{\mathrm{C}-\mathrm{Boron}}$ (Fig. 4B). The average KIE $\mathrm{C}_{\mathrm{B}-\mathrm{B} o r o n}$ from 12 DFT predictions for $\mathbf{6 B 3 - T M}$ Ts is 1.024(2) - a value that is in variance with the experimental KIE of 1.035(1). On the other hand, the predicted $\mathrm{KIE}_{\mathrm{C}-\mathrm{Boron}}$ for $\mathbf{8 B 4 - T M} \mathbf{M}_{\mathrm{TS}}$ is 1.034(1), which is in excellent agreement with experimental $\mathrm{KIE}_{\mathrm{C}-\mathrm{Boron}}$. On a side note, we also explored the intermolecular TM TS for transfer of the aryl group from an aryltrihydroxyborate to the $\mathrm{PdL}_{1}\left(\mathrm{Ar}_{1}\right)(\mathrm{Br}) \mathrm{OA}$ complex (inter-TMTs). While the predicted $\mathrm{KIE}_{\mathrm{C}-\mathrm{B} o r o n}$ for this $\mathrm{TS}$ is in reasonable agreement with experiment, it is $7.0 \mathrm{kcal} / \mathrm{mol}$ higher in energy than $\mathbf{8 B 4}-\mathbf{T} \mathbf{M}_{\mathrm{TS}}-$ suggesting that inter-TMTs is likely not the operative TM pathway (25). The quantitative match of experimental $(\sim 1.035)$ and predicted $(\sim 1.034) \mathrm{KIE}_{\mathrm{C}-\mathrm{Boron}}$ for $\mathbf{8 B 4}-\mathbf{T} \mathbf{M}_{\mathrm{Ts}}$ provides the first quantitative evidence for the transition structure of the TM step in the Suzuki-Miyaura reaction under catalytic conditions. We obtained identical $\mathrm{KIE}_{\mathrm{C}-\mathrm{Boron}}(1.035(2))$ when the reaction was performed with aryl bromides and in the presence of $5 \mathrm{~mol} \%$ added triphenylphosphine, suggesting that the TM step was unaffected by these modifications to reaction conditions (see Table S10 in Supplementary Information for details of these experiments).

In conclusion, we have utilized a combination of experimental and theoretical ${ }^{13} \mathrm{C}$ KIEs to delineate the fine details of the catalytic mechanism of the $\mathrm{Pd}\left(\mathrm{PPh}_{3}\right)_{4}$ catalyzed Suzuki-Miyaura reaction of aryl halides and aryl boronic acids. Our studies provide the first experimentally

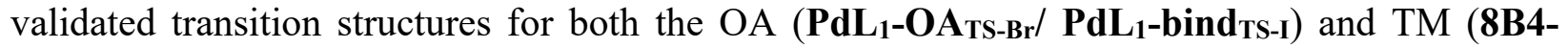
TM $\mathbf{M}_{\text {TS }}$ ) steps in the catalytic reaction, leading to a more detailed description of the catalytic cycle (Fig. 5). The reaction is initiated by dissociation of two phosphine ligands (L) from $\mathrm{PdL}_{4}$ to form the 14-electron $\mathrm{PdL}_{2}$ complex. During the first turnover, our experimental $\mathrm{KIE}_{\mathrm{C}-\mathrm{Br}}$ from the stoichiometric OA reaction (Fig. 2C) suggests that $\mathrm{PdL}_{2}$ is likely the palladium (0) species that

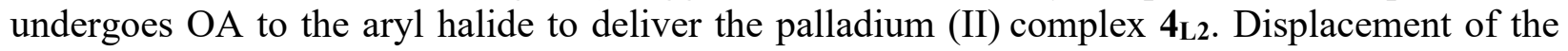
halide ligand by hydroxide likely results in the hydroxo-palladium complex $\mathbf{5}_{\mathbf{L} 2}$, which presumably undergoes ligand dissociation and coordination to 2a to form the pre-TM 8B4 intermediate. Our experimental $\mathrm{KIE}_{\mathrm{C}-\mathrm{B} o r o n}$ supports transmetalation occurring from $\mathbf{8 B} 4$ resulting in the pre-RE 
intermediate $\mathbf{6}_{\mathbf{L} 1}$. Subsequent facile RE delivers the cross-coupled biaryl $\mathbf{3}$ and generates the highly reactive, 12-electron $\mathrm{PdL}_{1}$ complex.

\section{$\mathrm{PdL}_{2}$ pathway}

- stoichiometric reaction

- excess ligand conditions
PdL $_{1}$ pathway

- catalytic reaction after first turnover
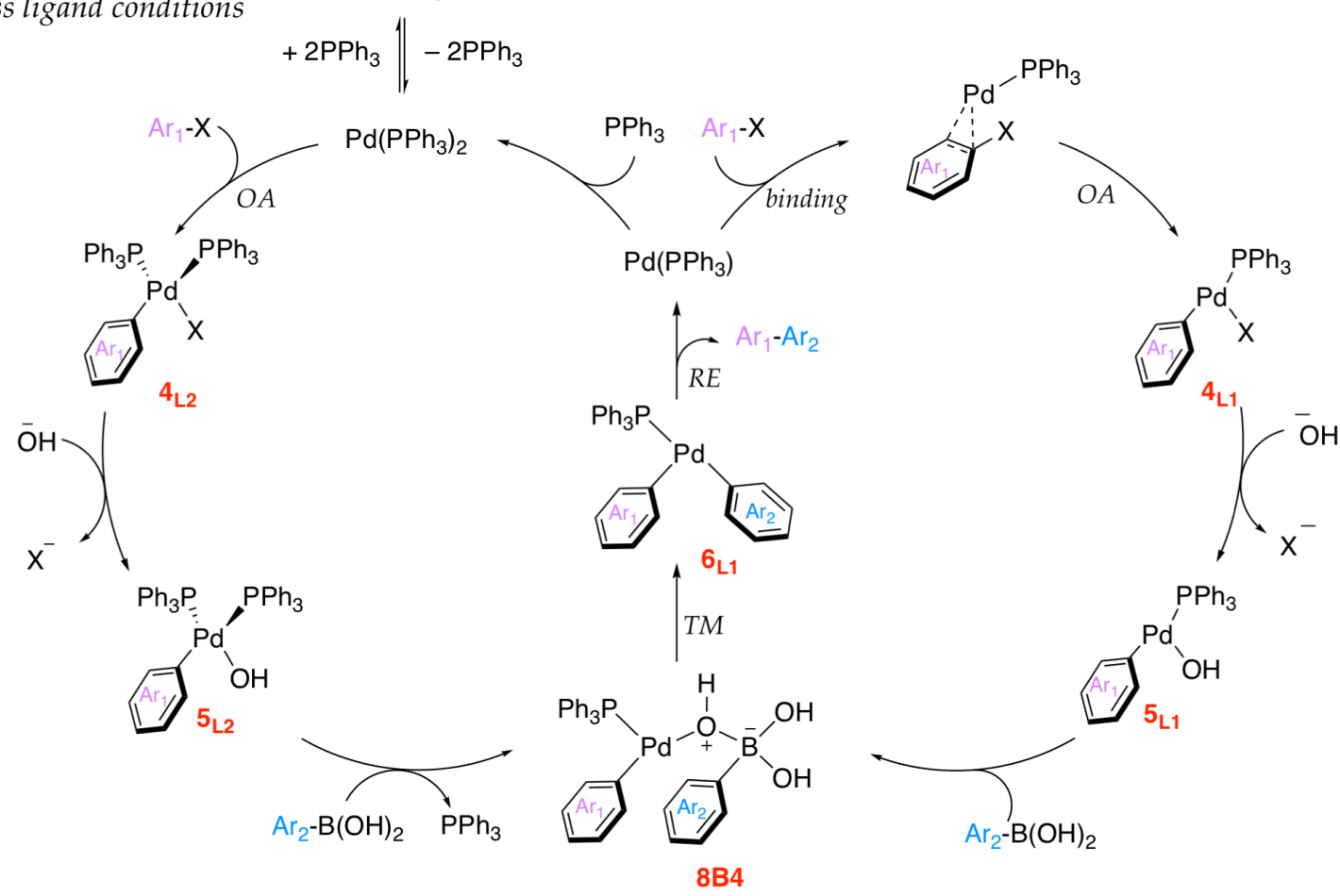

Fig. 4. The catalytic mechanism of the Suzuki-Miyaura reaction as determined herein using a combination of ${ }^{13} \mathrm{C}$ KIEs and DFT calculations

After the first turnover, the mechanism of subsequent catalytic cycles depends on the nature of the aryl halide and the concentration of the phosphine ligand in solution. Experimental KIE $\mathrm{C}_{\mathrm{C}-\mathrm{Br}}$ and $\mathrm{KIE}_{\mathrm{C}-\mathrm{I}}$ determined under standard catalytic conditions $\left(1 \mathrm{~mol} \% \mathrm{Pd}\left(\mathrm{PPh}_{3}\right)_{4}\right.$ and no added $\left.\mathrm{PPh}_{3}\right)$ support OA occurring to the $\mathrm{PdL}_{1}$ complex via a two-step process - (i) formation of an $\eta^{2}$ binding complex between $\mathrm{PdL}_{1}$ and the aryl halide, and (ii) $\mathrm{OA}$ of $\mathrm{PdL}_{1}$ into the $\mathrm{C}-\mathrm{X}$ bond to form the palladium (II) complex $\mathbf{4}_{\mathbf{L} 1}$. For aryl iodides, we have shown that the binding event is the first irreversible step whereas aryl bromides proceed via reversible binding followed by OA as the first irreversible step. Displacement of the halide from $\mathbf{4}_{\mathbf{L} 1}$ by hydroxide results in the mono-ligated hydroxopalladium complex $\mathbf{5}_{\mathbf{L} 1}$, which coordinates to the aryl boronic acid to directly yield the pre-TM intermediate 8B4. Subsequent TM and RE completes the catalytic cycle and regenerates $\mathrm{PdL}_{1}$. We anticipate that this unprecedented insight into the S-M reaction under catalytic conditions will inspire similar investigations of long-standing mechanistic questions in other areas of transition-metal catalysis.

\section{References and Notes:}

20 1. R. Stürmer, Organometallics in Process Chemistry. Advanced Synthesis \& Catalysis 346, 1501-1501 (2004). doi: 10.1002/adsc.200404292 
2. A. Biffis, P. Centomo, A. Del Zotto, M. Zecca, Pd Metal Catalysts for Cross-Couplings and Related Reactions in the 21st Century: A Critical Review. Chemical Reviews 118, 2249-2295 (2018). doi: 10.1021/acs.chemrev.7b00443

3. S. D. Roughley, A. M. Jordan, The Medicinal Chemist's Toolbox: An Analysis of Reactions Used in the Pursuit of Drug Candidates. Journal of Medicinal Chemistry 54, 3451-3479 (2011). doi: $10.1021 / \mathrm{jm} 200187 \mathrm{y}$

4. N. Miyaura, A. Suzuki, Palladium-catalyzed cross-coupling reactions of organoboron compounds. Chemical reviews 95, 2457-2483 (1995). doi: 10.1021/cr00039a007

5. A. Suzuki, Recent advances in the cross-coupling reactions of organoboron derivatives with organic electrophiles, 1995-1998. Journal of Organometallic Chemistry 576, 147168 (1999). doi: 10.1016/S0022-328X(98)01055-9

6. N. Miyaura, K. Yamada, H. Suginome, A. Suzuki, Novel and convenient method for the stereo-and regiospecific synthesis of conjugated alkadienes and alkenynes via the palladium-catalyzed cross-coupling reaction of 1-alkenylboranes with bromoalkenes and bromoalkynes. Journal of the American Chemical Society 107, 972-980 (1985). doi: $10.1021 / \mathrm{ja} 00290 \mathrm{a} 037$

7. G. B. Smith, G. C. Dezeny, D. L. Hughes, A. O. King, T. R. Verhoeven, Mechanistic studies of the Suzuki cross-coupling reaction. The Journal of Organic Chemistry 59, 81518156 (1994). doi: 10.1021/jo00105a036

20 8. K. Matos, J. A. Soderquist, Alkylboranes in the Suzuki- Miyaura coupling: Stereochemical and mechanistic studies. The Journal of organic chemistry 63, 461-470 (1998). doi: 10.1021/jo971681s

9. A. A. Braga, G. Ujaque, F. Maseras, A DFT study of the full catalytic cycle of the SuzukiMiyaura cross-coupling on a model system. Organometallics 25, 3647-3658 (2006). doi: 10.1021/om060380i

10. J. Jover, N. Fey, M. Purdie, G. C. Lloyd-Jones, J. N. Harvey, A computational study of phosphine ligand effects in Suzuki-Miyaura coupling. Journal of Molecular Catalysis A: Chemical 324, 39-47 (2010). doi: 10.1016/j.molcata.2010.02.021

11. C. Amatore, A. Jutand, G. Le Duc, Kinetic Data for the Transmetalation/Reductive Elimination in Palladium-Catalyzed Suzuki-Miyaura Reactions: Unexpected Triple Role of Hydroxide Ions Used as Base. Chemistry-A European Journal 17, 2492-2503 (2011). doi: 10.1002/chem.201001911

12. A. A. Thomas, S. E. Denmark, Pre-transmetalation intermediates in the Suzuki-Miyaura reaction revealed: The missing link. Science 352, 329-332 (2016). doi: 10.1126/science.aad6981

13. A. A. Thomas, H. Wang, A. F. Zahrt, S. E. Denmark, Structural, kinetic, and computational characterization of the elusive arylpalladium (II) boronate complexes in the SuzukiMiyaura reaction. Journal of the American Chemical Society 139, 3805-3821 (2017). doi: $10.1021 /$ jacs.6b13384

14. A. A. Thomas, A. F. Zahrt, C. P. Delaney, S. E. Denmark, Elucidating the role of the boronic esters in the Suzuki-Miyaura reaction: Structural, kinetic, and computational investigations. Journal of the American Chemical Society 140, 4401-4416 (2018). doi: $\underline{10.1021 / \mathrm{jacs} .8 \mathrm{~b} 00400}$

15. C. Amatore, F. Pfluger, Mechanism of oxidative addition of palladium (0) with aromatic iodides in toluene, monitored at ultramicroelectrodes. Organometallics 9, 2276-2282 (1990). doi: 10.1021/om00158a026 
16. C. Amatore, M. Azzabi, A. Jutand, Role and effects of halide ions on the rates and mechanisms of oxidative addition of iodobenzene to low-ligated zerovalent palladium complexes Pd0 (PPh3) 2. Journal of the American Chemical Society 113, 8375-8384 (1991). doi: 10.1021/ja00022a026

17. C. Amatore, A. Jutand, F. Khalil, M. A. M'Barki, L. Mottier, Rates and mechanisms of oxidative addition to zerovalent palladium complexes generated in situ from mixtures of Pd0 (dba) 2 and triphenylphosphine. Organometallics 12, 3168-3178 (1993). doi: 10.1021/om00032a045

18. J. F. Hartwig, F. Paul, Oxidative addition of aryl bromide after dissociation of phosphine from a two-coordinate palladium (0) complex, bis (tri-o-tolylphosphine) palladium (0). Journal of the American Chemical Society 117, 5373-5374 (1995). doi: $\underline{10.1021 / \mathrm{ja} 00124 \mathrm{a} 026}$

19. A. L. Casado, P. Espinet, On the configuration resulting from oxidative addition of RX to $\mathrm{Pd}(\mathrm{PPh} 3) 4$ and the mechanism of the cis-to-trans isomerization of [PdRX (PPh3) 2] complexes $(\mathrm{R}=$ aryl, $\mathrm{X}=$ halide). Organometallics 17, 954-959 (1998). doi: $\underline{10.1021 / o m 9709502}$

20. C. Amatore, A. Jutand, Mechanistic and kinetic studies of palladium catalytic systems. Journal of organometallic chemistry 576, 254-278 (1999). doi: 10.1016/S0022328X(98)01063-8

20 21. H. M. Senn, T. Ziegler, Oxidative addition of aryl halides to palladium (0) complexes: a density-functional study including solvation. Organometallics 23, 2980-2988 (2004). doi: 10.1021/om049963n

22. T. R. Cundari, J. Deng, Density functional theory study of palladium-catalyzed arylnitrogen and aryl-oxygen bond formation. Journal of physical organic chemistry 18, 417 425 (2005). doi: 10.1002/poc.889

23. M. Ahlquist, P. Fristrup, D. Tanner, P.-O. Norrby, Theoretical evidence for low-ligated palladium (0): $[\mathrm{Pd}-\mathrm{L}]$ as the active species in oxidative addition reactions. Organometallics 25, 2066-2073 (2006). doi: 10.1021/om060126q

24. F. Barrios-Landeros, B. P. Carrow, J. F. Hartwig, Effect of ligand steric properties and halide identity on the mechanism for oxidative addition of haloarenes to trialkylphosphine Pd (0) complexes. Journal of the American Chemical Society 131, 8141-8154 (2009). doi: $10.1021 / \mathrm{ja} 900798 \mathrm{~s}$

25. B. P. Carrow, J. F. Hartwig, Distinguishing between pathways for transmetalation in Suzuki- Miyaura reactions. Journal of the American Chemical Society 133, 2116-2119 (2011). doi: 10.1021/ja1108326

26. C. Amatore, A. Jutand, G. Le Duc, Mechanistic Origin of Antagonist Effects of Usual Anionic Bases $(\mathrm{OH}-, \mathrm{CO} 32-)$ as Modulated by their Countercations $(\mathrm{Na}+, \mathrm{Cs}+, \mathrm{K}+)$ in Palladium-Catalyzed Suzuki-Miyaura Reactions. Chemistry-A European Journal 18, 6616-6625 (2012). doi: 10.1002/chem.201200516

40 27. M. García-Melchor, A. A. C. Braga, A. Lledós, G. Ujaque, F. Maseras, Computational Perspective on Pd-Catalyzed C-C Cross-Coupling Reaction Mechanisms. Accounts of Chemical Research 46, 2626-2634 (2013). doi: 10.1021/ar400080r

28. P. Veerakumar, P. Thanasekaran, K.-L. Lu, K.-C. Lin, S. Rajagopal, Computational Studies of Versatile Heterogeneous Palladium-Catalyzed Suzuki, Heck, and Sonogashira Coupling Reactions. ACS Sustainable Chemistry \& Engineering 5, 8475-8490 (2017). doi: 10.1021/acssuschemeng. 7b00922 
29. T. Yaman, J. N. Harvey, Suzuki-Miyaura coupling revisited: an integrated computational study. Faraday Discussions 220, 425-442 (2019). doi: 10.1039/C9FD00051H

30. D. A. Singleton, A. A. Thomas, High-Precision Simultaneous Determination of Multiple Small Kinetic Isotope Effects at Natural Abundance. Journal of the American Chemical Society 117, 9357-9358 (1995). doi: 10.1021/ja00141a030

31. B. R. Beno, K. N. Houk, D. A. Singleton, Synchronous or Asynchronous? An "Experimental" Transition State from a Direct Comparison of Experimental and Theoretical Kinetic Isotope Effects for a Diels-Alder Reaction. Journal of the American Chemical Society 118, 9984-9985 (1996). doi: 10.1021/ja9615278

10 32. J. S. Hirschi, T. Takeya, C. Hang, D. A. Singleton, Transition-State Geometry Measurements from 13C Isotope Effects. The Experimental Transition State for the Epoxidation of Alkenes with Oxaziridines. Journal of the American Chemical Society 131, 2397-2403 (2009). doi: 10.1021/ja8088636

33. J. Y. Wang, A. E. Strom, J. F. Hartwig, Mechanistic Studies of Palladium-Catalyzed Aminocarbonylation of Aryl Chlorides with Carbon Monoxide and Ammonia. Journal of the American Chemical Society 140, $7979-7993$ (2018). doi: 10.1021/jacs.8b04073

34. R. Giri, A. Brusoe, K. Troshin, J. Y. Wang, M. Font, J. F. Hartwig, Mechanism of the Ullmann Biaryl Ether Synthesis Catalyzed by Complexes of Anionic Ligands: Evidence for the Reaction of Iodoarenes with Ligated Anionic CuI Intermediates. Journal of the American Chemical Society 140, 793-806 (2018). doi: 10.1021/jacs.7b11853

35. N. Yoshikai, H. Matsuda, E. Nakamura, Ligand Exchange as the First Irreversible Step in the Nickel-Catalyzed Cross-Coupling Reaction of Grignard Reagents. Journal of the American Chemical Society 130, 15258-15259 (2008). doi: 10.1021/ja807000a

36. K. P. Gable, F. A. Zhuravlev, Kinetic Isotope Effects in Cycloreversion of Rhenium (V) Diolates. Journal of the American Chemical Society 124, 3970-3979 (2002). doi: $10.1021 / \mathrm{ja} 017736 \mathrm{w}$

37. A. A. Kurokhtina, E. V. Larina, A. F. Schmidt, Measuring the kinetic isotope effect at natural isotopic abundances for discriminating between the homogeneous and heterogeneous catalytic mechanisms in the Heck and Suzuki reactions. Kinetics and Catalysis 57, 32-38 (2016). doi: 10.1134/S0023158415060063

38. F. Kakiuchi, H. Ohtaki, M. Sonoda, N. Chatani, S. Murai, Mechanistic study of the Ru (H) $2(\mathrm{CO})(\mathrm{PPh} 3)$ 3-catalyzed addition of $\mathrm{C}-\mathrm{H}$ bonds in aromatic esters to olefins. Chemistry letters 30, 918-919 (2001). doi: 10.1134/S0023158415060063

39. N. Yoshikai, E. Nakamura, Mechanism of Substitution Reaction on sp2-Carbon Center with Lithium Organocuprate. Journal of the American Chemical Society 126, 12264-12265 (2004). doi: 10.1021/ja046616w

40. M. G. Hyatt, D. J. Walsh, R. L. Lord, J. G. Andino Martinez, D. Guironnet, Mechanistic and Kinetic Studies of the Ring Opening Metathesis Polymerization of Norbornenyl Monomers by a Grubbs Third Generation Catalyst. Journal of the American Chemical Society 141, 17918-17925 (2019). doi: 10.1021/jacs.9b09752

41. H. Lee, M. V. Mane, H. Ryu, D. Sahu, M.-H. Baik, C. S. Yi, Experimental and Computational Study of the (Z)-Selective Formation of Trisubstituted Olefins and BenzoFused Oxacycles from the Ruthenium-Catalyzed Dehydrative $\mathrm{C}-\mathrm{H}$ Coupling of Phenols with Ketones. Journal of the American Chemical Society 140, 10289-10296 (2018). doi: $\underline{10.1021 / j a c s .9 b 09752}$ 
42. D. J. Jones, M. Lautens, G. P. McGlacken, The emergence of Pd-mediated reversible oxidative addition in cross coupling, carbohalogenation and carbonylation reactions. Nature Catalysis 2, 843-851 (2019). doi: 10.1038/s41929-019-0361-0

43. A. H. Roy, J. F. Hartwig, Reductive Elimination of Aryl Halides from Palladium(II). Journal of the American Chemical Society 123, 1232-1233 (2001). doi: 10.1021/ja0034592

\section{Acknowledgments:}

Funding: Research reported in this publication was supported by the National Institutes of Health under R01 GM126283 (M.J.V.) and Binghamton University startup funds (J.S.H.). M.J.V and J.S.H. acknowledge support from the XSEDE Science Gateways Program (allocation IDs 10 CHE160009 and CHE180061), which is supported by the National Science Foundation grant number ACI-1548562. Author contributions: M.J.V. and J.S.H. conceived of and directed the research and prepared the manuscript. J.M.M., C.J., and S.K. performed all the experiments reported in the manuscript. C.J., J.A.I., and V.W. performed the computations reported in the manuscript. Competing interests: The authors declare no conflicts of interest. Data and 15 materials availability: All data is available in the main text or the supplementary materials."

Supplementary Materials:

Materials and Methods

Tables S1-S22

References (1-59) 